\title{
Diamond-Like-Carbon Coatings for Advanced Biomedical Applications
}

\author{
Rajib Paul* \\ Department of Mechanical and Aerospace Engineering, Case Western Reserve University, USA
}

Submission: July 11, 2017; Published: August 23, 2017

*Corresponding author: Rajib Paul, Department of Mechanical and Aerospace Engineering, Case Western Reserve University, USA, Tel: 216-368-2000; Email: rxp348@case.edu; rajiv2008juniv@gmail.com

\begin{abstract}
Graphene and carbon nanotubes are widely spread carbon allotropes for advanced nanotechnological applications. However, they are not popular for biomedical applications due to cytotoxic effects. In this respect diamond-like carbon (DLC), being mechanically stable and noncytotoxic, is spreading rapidly for protective coatings in orthopedic and stent research. Very recently, DLC through proper functionalization, is emerging as potential material for advanced applications, such as, biomolecular monitoring, cancer therapy and neural cell culture etc. This review summarizes the important biomedical advancements of DLC coatings.
\end{abstract}

Keywords: Diamond-like carbon; Cytotoxic; Surface-plasmon resonance; Antithrombogenic; Cancer; Neural-cell

Abbreviations: DLC: Diamond-Like Carbon; ALP: Alkaline Phosphatase; SPR: Surface Plasmon Resonance

\section{Introduction}

Diamond-like carbon (DLC) is considered as a versatile coating material that finds a variety of mechanical and biomedical applications, including endoprosthesis and dental implants [1]. It provides mechanical robustness and cell-compatibility at the same time. Therefore, DLC has been extensively researched for achieving high hardness, low friction, high wear resistance to make it more sustainable [2]. Furthermore, DLC coatings are antithrombogenic and noncytotoxic. Consequently, they are being critically explored for various in-vivo and in-vitro biomedical applications ranging from orthopaedic applications to cardiovascular as well as neural interfacing agent. As such, DLC coatings has been certified as biocompatible in both in vitro and in vivo studies due to their strong $\mathrm{C}-\mathrm{C}$ bonding environment $[3,4]$.

In this article, the recent biomedical applications of DLC coatings have been briefly discussed together with promising prospects. The properties of DLC coatings can be tailored by manipulating the bonding environment between $\mathrm{sp}^{3}$ and $\mathrm{sp}^{2}$ hybridized carbon atoms and their relative contents. In DLC, the $\mathrm{sp}^{3}$ hybridized carbon (diamond) which is responsible for excellent mechanical properties, is irregularly mixed with the $\mathrm{sp}^{2}$ carbon (graphite) which generally acts as filler contents within $\mathrm{sp}^{3}$ carbon matrix, and therefore justifies the name, diamond-like carbon [5].

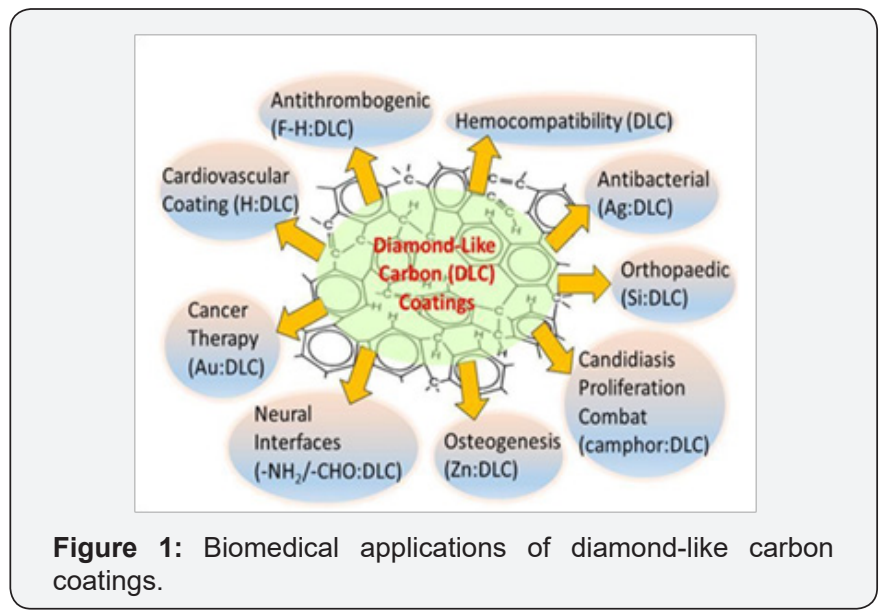

However, the general functionality of DLC films depends on the $\mathrm{sp}^{2} / \mathrm{sp}^{3}$ ratio which can be varied within a certain limit depending on the synthesis technique and conditions. Therefore, different metal nanoparticles $\mathrm{CAu}, \mathrm{Ag}, \mathrm{Si}, \mathrm{Cu}, \mathrm{Cr}, \mathrm{Ti}, \mathrm{Ni}, \mathrm{Zn}, \mathrm{Fe}, \mathrm{W}$, $\mathrm{V}$ etc.) and non-metal elements (H, N, F, B, $\mathrm{O}$ etc.) are doped into DLC films to tailor the physical and chemical properties suitable 
for different biomedical applications [6]. Figure 1 illustrates pure DLC structure and summarizes important biomedical applications with different types of DLC coatings. DLC coatings for orthopedic and dental applications are well explored. For knee and hip joints, pure DLC coatings are not suitable because the peak loads reach upto 3.4-3.9 times higher than the body weight [7]. Moreover, both $\mathrm{sp}^{3}-\mathrm{C}$ and hydrogen $(\mathrm{H})$ content influence the mechanical properties in DLC and as such, a high $\mathrm{sp}^{3}$ fraction can lead to delamination of the coatings on metal surfaces due to compressive internal stress generated during synthesis process [6].

For such applications, Si doped DLC (Si: DLC) is utilized due to its low friction coefficient and high wear resistance against sliding and mechanical forces. For applications where biomechanical stability of DLC coatings is concerned, the important parameters are low surface energy, low friction, low roughness, high thermal stability, low wear, low electrical resistivity, and high biocompatibility which can be achieved through different metal $(\mathrm{Si}, \mathrm{Cr}, \mathrm{Ti})$ or non-metal $(\mathrm{N}, \mathrm{H}, \mathrm{B})$ doping or strategic combination of both metal and nonmetal elements, such as, Si doped carbon nitride films for efficient biocompatible and orthopedic applications [8]. DLC surface energy and roughness dictate the cellular response and hemocompatibility. Such properties are also essential for cardiovascular implantable devices particularly stents [9]. As compared to other synthesis techniques, DLC coatings processed through different plasma depositions are usually certified as hemocompatible/ biocompatible as they can prevent the adhesion and activation of platelets and preferentially promote the adsorption of albumin over fibrinogen.

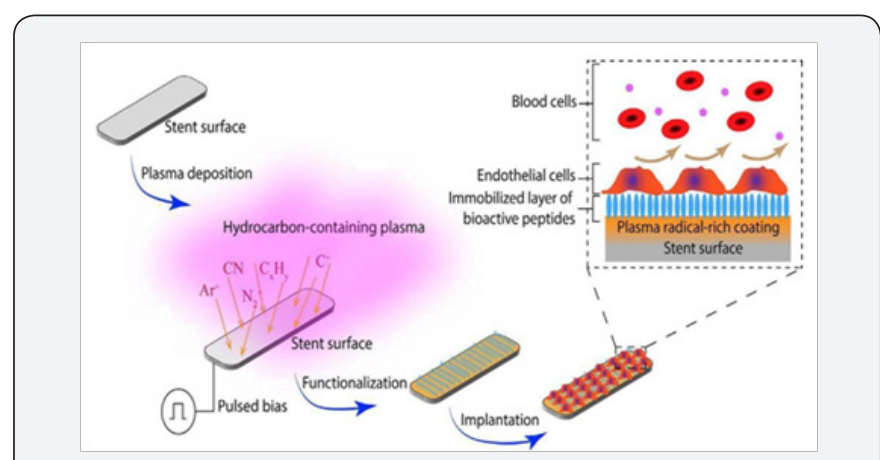

Figure 2: Proactive biofunctionalization of coronary stents using plasma discharges in carbon-based atmospheres. The stent is electrically biased to accelerate plasma positive ions towards the growing coating, creating therefore a radical-rich plasma activated coating (PAC). [9, copyright to Elsevier (2015)].

Recent advances suggest that plasma enhanced chemical vapour deposition can be used to prepare DLC films that allow for the linker-free immobilization of bioactive molecules (Figure 2) $[7,9]$. The excellent antithrombogenic properties of DLC coating, such as, amorphous hydrogenated DLC (a-C:H), P-doped DLC [10], fluorine and hydrogen co-doped DLC (a-C:H:F) which is maintained over 30 days and temperature upto $90{ }^{\circ} \mathrm{C}$ and hence promises for a commercialized stent coating material for nextgeneration medical devices [11]. Osteogenesis is a genetic disorder characterized by bones that break easily, often from little or no apparent cause. DLC have demonstrated improvement in the propagation of osteoblasts particularly for in vitro conditions. Titanium oxide (TiO2) doped DLC and DLC coated silicon nitride (Si3N4) substrate are also considerable in such respect $[12,13]$. Recently, Zn doped DLC, is reported from which the amount of released $\mathrm{Zn}$ ions is controlled by altering the manufacturing process [14].

The Zn:DLC coating enhances the calcification of an osteoblast cell line via an alkaline phosphatase (ALP) independent mechanism which is promising for curing osteogenesis. Candidias is contamination is related to parenteral nutrition, and it is transmitted through the hands of healthcare workers and especially through use of catheters. It is a big problem for hospitalized patients, especially those in critical condition, and is the fourth leading cause of bloodstream infection [15]. Santos et al. [16] has recently used camphor containing DLC coating to prevent the Candida albicans yeasts fouling on polyurethane substrate which is commonly used for catheter manufacturing. The camphor:DLC and DLC films reduced the biofilm growth by $99.0 \%$ and $91.0 \%$ of Candida albicans, respectively, compared to bare polyurethane. These results promise the utilization of functionalized DLC coatings with biofilm inhibition properties for production of advanced catheters or for other biomedical applications.

Silver nanoparticle (Ag NP) doped DLC is efficient for antibacterial coating applications [17]. Ag NPs react with sulfurrich proteins in the bacteria cell membrane and the interior of the cell or with phosphorous-containing compounds, such as DNA. Accordingly, the morphological changes in the bacteria cell membrane and the possible damage of DNA, caused by the reaction with Ag NPs, disturb the respiratory chain or cell division processes, leading to cell death [18]. The Ag NPs are known to get oxidized to Ag+ ions when they interact with water molecules. It is well agreed that the antimicrobial activity of $\mathrm{Ag}$ NP based nanocomposites is basically related to their ability to release Ag+ over time [19].

Recently, a new type of antibacterial bandage is proposed where Ag:DLC coated synthetic silk tissue is utilized as a building block [20]. The efficiency of the Ag+ ions released to the aqueous media is found to increase further through RF oxygen plasma etching of the Ag:DLC coating. The bandage prototype contains about 3.12 at $\% \mathrm{Ag}$ nanoparticles of diameter $23.7 \mathrm{~nm}$. This amount is well below the toxic level (upto 13.5 $\mu \mathrm{g} / \mathrm{mL}$ ) for organism cells and can kill more than $99.9 \%$ of all strains of bacteria after $320 \mathrm{~min}$, including methicillin-resistant Staphylococcus aureus.

Core-shelled structured DLC coatings with dispersed Ag and $\mathrm{Au}$ nanoparticles show excellent and stable surface plasmon 


\section{Global Journal of Nanomedicine}

resonance (SPR) properties [21,22]. Such structures are also effective to reduce the internal stress in DLC coatings $[6,23]$. This opens up for a DLC-SPR based label-free bio-detection method which has emerged during the last two decades as a suitable and reliable platform in clinical analysis for biomolecular interactions [24]. The technique makes it possible to measure interactions in real-time with high sensitivity and without the need of labels (Figure 3a). In recent years, SPR is being utilized for monitoring antibodies, proteins, enzymes, drugs, small molecules, peptides, and nucleic acids in biofluids collected from patients afflicted with a series of medical conditions (Alzheimer's, hepatitis, diabetes, leukemia, and cancers such as prostate and breast cancers, among others) which demonstrate the progress of SPR sensing in clinical chemistry $[24,25]$.

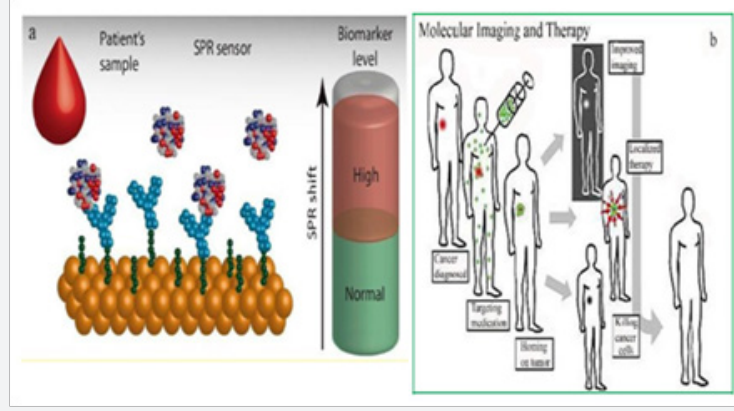

Figure 3: (a) Au nanoparticle based surface plasmon resonance aided biosensors for medical diagnostics [25, copyright to American Chemical Society (2017)], (b) The kanzius radio frequency therapy as cancer treatment method that is potential to replace the radiation and chemotherapy $[26$, copyright to Ispub.com (2007)].

Au:DLC and Ag:DLC coatings can become golden coating material for such applications. DLC/metal nanoparticles based core-shell structure is also promising for cancer treatment through photo-thermal therapy (PTT) which is a minimallyinvasive therapy in which photon energy is converted into heat to kill cancer (Figure 3b) [26,27]. Gold nanoparticles absorb light strongly and convert photon energy into heat quickly and efficiently, thereby making them superior contrast agents for PTT [28]. The superior SPR of Au:DLC core-shell structure could be very effective in this case.

DLC coatings has recently been evaluated as a growth substrate for neurons and Schwann cells which is quite interesting [29]. DLC is modified by UV functionalization method to introduce surface-bound amine (-NH2) and aldehyde (-CHO) groups. Such functionalization process increases the wettability of DLC which significantly increases the adhesion of neurons seeded to the surface. The amine functionalized DLC promotes adhesion of neurons and fosters neurite outgrowth to a degree indistinguishable from positive control substrates (glass coated with poly-L-lysine). Furthermore, aldehyde-functionalized DLC surfaces also show similar behavior and both additionally support the adhesion and growth of primary rat Schwann cells
(Figure 4). This demonstrates a way to harness these properties of DLC coatings for development of implantable advanced devices to interface with the nervous system.
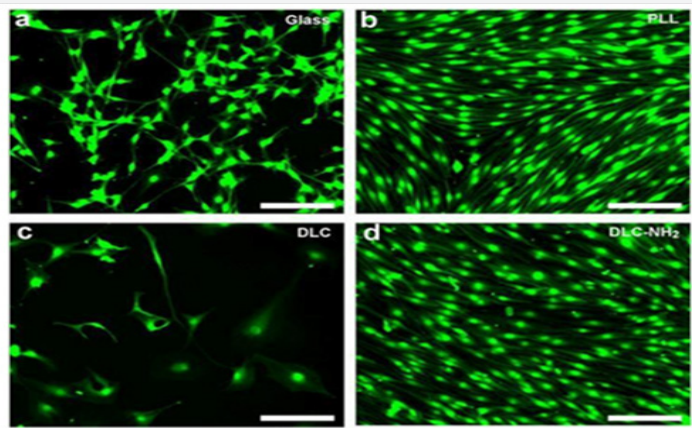

Figure 4: Fluorescence micrographs of primary rat Schwann cells cultured for 21 days. (a) Glass. (b) Poly-L-lysine (PLL), a synthetic adhesion factor commonly used in neural cell culture. (c) Pristine DLC. (d) DLC-NH2. Cells were immunolabelled for S100ß. Scale bars: $100 \mu \mathrm{m}$. [30, copyright to Elsevier (2016)].

Recently researchers have reported DLC coatings which are thermally stable upto $500{ }^{\circ} \mathrm{C}$ without compromising mechanical properties [30]. Furthermore, researchers are finding innovative ways to fabricate superior DLC coatings. For example, Erdemir et al. [31] have invented DLC tribofilms synthesized from lubricating oils which show excessively advanced mechanical properties. Such DLC coatings are potential to accelerate considerable advancement in its applicability and usefulness for various biomedical applications.

\section{Conclusion and prospect}

Diamond-like carbon coatings are very useful for different biomedical applications ranging not only to traditional orthopedic and cardiovascular applications but also for cancer treatment, functional coatings on stents, combating candidiasis proliferation as well as neural cell culture. The applicability of DLC coatings in biomedical fields depends on their mechanical and cytotoxic properties. Such properties are found to depend on the morphology, bonding environment and chemical properties of the DLC coatings. Although numerous attempts have been performed and are being explored to understand the mechanism for advanced biomedical application of DLC coatings through different metal and non-metal doping and surface activation through plasma-assisted techniques or chemical methods, more research focus is required to trigger a breakthrough in achieving biomedically practical DLC coatings.

\section{Acknowledgement}

The author wish to thank the peers for their works cited here.

\section{References}

1. Gotzmann G, Beckmann J, Wetzel C, Scholz B, Herrmann U, et al. (2017) Electron-beam modification of DLC coatings for biomedical applications. Surf Coat Technol 311(15): 248-256. 
2. Wei C, Peng KS, Hung MS (2016) The effect of hydrogen and acetylene mixing ratios on the surface, mechanical and biocompatible properties of diamond-like carbon films. Diam. Relat Mater 63: 108-114.

3. Hang R, Zhang M, Ma S, Chu PK (2012) Biological response of endothelial cells to diamond-like carboncoated NiTi alloy. J Biomed Mater Res Part A 100(2): 496-506.

4. Roy RK, Lee KR (2007) Biomedical applications of diamond-like carbon coatings: a review. J Biomed Mater Res B Appl Biomater 83(1): 72-84.

5. Paul R, Bhar R, Pal AK (2010) Field emission properties of composite nano-Au/DLC films prepared by CVD technique. Materials Research Bulletin 45(5): 576-583.

6. Paul R (2017) Uniformly dispersed nanocrystalline silver reduces the residual stress within diamond-like carbon hard coatings. NanoStructures \& Nano-Objects 10: 69-79.

7. Filova E, Vandrovcova M, Jelinek M, Zemek J, Houdkova J, et al. (2017) Adhesion and differentiation of Saos-2 osteoblast-like cells on chromium-doped diamond-like carbon coatings. J Mater Sci Mater Med 28(17): 1-14.

8. Liang Y, Liu DG, Bai WQ Tu JP (2017) Investigation of silicon carbon nitride nanocomposite films as a wear resistant layer in-vitro and in-vivo for joint replacement applications. Colloids and Surfaces B Biointerfaces 153: 41-51.

9. Santos M, Bilek MMM, Wise SG (2015) Plasma-synthesised carbonbased coatings for cardiovascular applications. Biosurface and Biotribology 1(3): 146-160.

10. Kwok SCH, Wang J, Chu PK (2005) Surface energy, wettability, and blood compatibility phosphorus doped diamond-like carbon films. Diam Relat Mater 14: 78-85.

11. Maegawa S, Hasebe T, Yamato Y, Bito K, Nagashima S, et al. (2016) Time course analysis of antithrombogenic properties of fluorinated diamond-like carbon coating determined via accelerated aging tests: Quality control for medical device commercialization. Diam Relat Mater 70: 33-38.

12. Randeniya LK, Bendavid A, Martin PJ, Amin MS, Rohanizadeh R, et al. (2010) Thin-film nanocomposites of diamond-like carbon and titanium oxide: Osteoblast adhesion and surface properties. Diam Relat Mater 19: 329-335.

13. Salgueiredo E, Vila M, Silva MA, Lopes MA, Santos JD, et al. (2008) Biocompatibility evaluation of DLC-coated Si3N4 substrates for biomedical applications. Diam Relat Mater 17: 878-881.

14. Katouno J, Fujioka K, Kidera S, Mabuchi Y, Sato K, et al. (2017) Evaluation of the enhancement of osteogenesis by Zn-releasing diamond-like carbon film. Diam Relat Mater 77: 131-136.

15. Bazaka K, Jacob MV, Crawford RJ, Ivanova EP (2012) Efficient surface modification of biomaterial to prevent biofilm formation and the attachment of microorganisms. Appl Microbiol Biotechnol 95(2): 299311.

16. Santos TB, Vieira AA, Paula LO, Santos ED, Radi PA, et al. (2017) Flexible camphor diamond-like carbon coating on polyurethane to prevent Candida albicans biofilm growth. J Mech Behav Biomed Mater 68: $239-246$
17.Schwarz FP, Hauser-Gerspach I, Waltimo T, Stritzker B (2011) Antibacterial properties of silver containing diamond like carbon coatings produced by ion induced polymer densification. Surf Coat Technol 205: 4850-4854.

18. Lazic V, Saponjic Z, Vodnik V, Dimitrijevic S, Jovancic P, et al. (2012) study of the antibacterial activity and stability of dyed cotton fabrics modified with different forms of silver. J Serbian Chem Soc 77: 225234 .

19. Palomba M, Carotenuto G, Cristino L, Grazia MAD, Nicolais F, et al. (2012) Activity of antimicrobial silver polystyrene nanocomposites. J. Nanomater 185029: 1-7.

20. Juknius T, Ružauskas M, Tamulevicius T, Šiugždiniene R, Juknien I, et al. (2016) Antimicrobial Properties of Diamond-Like Carbon/Silver Nanocomposite Thin Films Deposited on Textiles: Towards Smart Bandages. Materials 9(5): 371 1-3715.

21. Paul R, Hussain S, Majumder S, Varma S, Pal AK (2009) Surface plasmon characteristics of nanocrystalline gold/DLC composite films prepared by plasma CVD technique. Materials Science and Engineering: B 164(3): 156-164.

22. Paul R, Dey A, Mukherjee AK, Sarangi SN, Pal AK (2012) Effect of nanocrystalline silver impregnation on mechanical properties of diamond-like-carbon films by nano-indentation. Ind J Pure Appl Phys 50: 252-259.

23. Paul R, Bhattacharyya SR, Bhar R, Pal AK (2011) Modulation of residual stress in diamond like carbon films with incorporation of nanocrystalline gold. Applied Surface Science 257(24): 10451-10458.

24. Nguyen HH, Park J, Kang S, Kim M (2015) Surface Plasmon Resonance: A Versatile Technique for Biosensor Applications. Sensors 15(5): 10481-10510

25. Masson JF (2017) Surface Plasmon Resonance Clinical Biosensors for Medical Diagnostics. ACS Sensors 2(1): 16-30.

26. Huang X, El-Sayed MA (2011) Plasmonic photo-thermal therapy (PPTT). Alexandria Journal of Medicine 47(1): 1-9.

27. Sonal S, Prabhakar V, Aneesh T, Sabitha M (2007) Nanomedicine: Promise of the future in disease

management. The Internet Journal of Nanotechnology 2(2): 1-6.

28. Letfullin RR, George TF (2016) Computational Nanomedicine and Nanotechnology (Chapter 3) Introduction to Cancer Therapy and Detection by Plasmonic Nanoparticles: page-133. Springer International Publishing Gewerbestrasse 11, Switzerland.

29. Hopper AP, Dugan JM, Gill AA, Regan EM, Haycock JW, et al. (2016) Photochemically modified diamond-like carbon surfaces for neural interfaces. Mater Sci Eng C Mater Biol Appl 58: 1199-1206.

30. Ray SC, Bhattacharya G, Miller MA, Sarma S, Upadhay RK (2017) A facile method for the deposition of thermally stable diamond like carbon thin films via carbon dioxide precursor gas. Diam Relat Mater 73: 93-98.

31. Erdemir A, Ramirez G, Eryilmaz OL, Narayanan B, Liao Y, et al. (2016) Carbon-based tribofilms from lubricating oils. Nature 536(7614): 6771. 
(CC) This work is licensed under Creative (C) Commons Attribution 4.0 License BY DOI: 10.19080/GJN.2017.02.555598

\section{Your next submission with JuniperPublishers} will reach you the below assets

- Quality Editorial service

- Swift Peer Review

- Reprints availability

- E-prints Service

- Manuscript Podcast for convenient understanding

- Global attainment for your research

- Manuscript accessibility in different formats

( Pdf, E-pub, Full Text, Audio)

- Unceasing customer service

Track the below URL for one-step submission https://juniperpublishers.com/submit-manuscript.php 